\title{
Validation of the General Health Questionnaire (GHQ-12) adapted to a work-related context
}

\author{
Francois-Xavier Lesage ${ }^{1,2^{\star}}$, Sonia Martens-Resende ${ }^{2}$, Frédéric Deschamps $^{2}$, Sophie Berjot $^{1}$ \\ ${ }^{1}$ Laboratory of Applied Psychology-LPA-(EA4298), Reims, France; ${ }^{*}$ Corresponding author: fxlesage@chu-reims.fr \\ ${ }^{2}$ Occupational Health Department, Faculty of Medicine, Hôpital Sébastopol, Reims, France.
}

Received 25 May 2011; revised 14 July 2011; accepted 31 July 2011.

\begin{abstract}
Introduction: the aim of this study is to test the factorial structure and the internal consistency of the 12-items General Health Questionnaire adapted to work-related psychological distress (GHQW). Methods: a validated French version of the GHQ-12 was used and transformed to remind of the occupational context. A sample of 1014 workers completed the GHQW. Internal consistency was assessed by Cronbach's $\alpha$ coefficient. The factorial structure was extracted with an exploratory factorial analysis (EFA). Results: the EFA run on the data yield to a onefactor structure explaining $60.5 \%$ of the total variance of the scale. The Cronbach's alpha showed a very good internal consistency of the scale $(\alpha=0.94)$. Conclusion: the findings support that the GHQW is a reliable and valid instrument for measuring work-related psychological distress in workers. This work-related version could find some applications in epidemiological research at work, in the study of psychosocial risk factors and in the occupational health physician's daily activity.
\end{abstract}

Keywords: Occupational Health; Mental Health; Questionnaires; Factor Analysis; Statistical; General Health Questionnaire; Validity

\section{INTRODUCTION}

The 12-item General Health Questionnaire (GHQ-12) is a self-report measure of psychological morbidity, intended to detect psychiatric disorders in community settings and non-psychiatric settings [1]. It is widely used in clinical practice, epidemiological research and for research in psychology [2-4].

The original GHQ is composed of 60 items. However, different shortened validated versions of this instrument are currently available (e.g., 30, 28, and 12-items).

The 12-items version, due to its brevity, is probably the most popular and so, has been extensively evaluated in terms of its validity and reliability as a one-dimensional indicator of the severity of psychological morbidity [5-9].

Respondents had to indicate, on a -points scale anchored with 1) less than usual, 2) no more than usual, 3) rather more than usual, 4) much more than usual how frequently they experienced recently the different symptoms listed on the scale. The general version of the scale does not precise to participants any context in which the symptoms have been experienced. Each item is rated on a four-point scale, using one of two most common scoring methods: dichotomous (0-0-1-1) or Likert-like type (0-1-2-3).

The GHQ-12 is a well-known instrument for measuring minor psychological distress and has been translated into a variety of languages. If the GHQ-12 is not a tool for indicating a specific diagnosis (e.g. depression, anxiety, etc.), it is more useful and adapted in the work context in the way that it can serve as an general indicator of distress and/or potential problems.

The GHQ-12 was designed and is used routinely as an unidimensional measure of psychological morbidity. Many studies, however, have reported that the GHQ-12 is not unidimensional, but instead assesses psychological morbidity in two (positive and negative items) or three dimensions ("anxiety and depression”, "social dysfunction" and "loss of confidence") [10-19].

Considering the GHQ-12 to be a brief, simple and easy to complete instrument, and thefact that its application in research settings as a screening tool is well documented, we decidedto check its psychometric properties in a work-related version.

This version could find some applications in epidemiological research at work, in the study of psychosocial risk factors and in the occupational health physician's daily activity. 


\section{MATERIALS AND METHODS}

\subsection{Participants}

One thousand and fourteen workers were randomly selected in an occupational health center (In the French occupational health organization, every workers have a systematic medical examination annually or biennially).

At their arrival at the center, the authors, after having informed the participants about the study objectives, ask for their voluntary and anonymous participation in the study, précising that they could withdraw at any time. Both oral and written instructions were given to ensure that the items were understood, and participants were reassured that their responses were confidential.

\subsection{Instrument}

A modified version of the GHQ-12 validated French scale was used [12]. The first modification was made on the instructions, which (orally and written) asked whether the participants experienced recently at work the symptoms and/or behaviors listed on the scale. The second modification was made on the items of the scale. For each item is now précised the work context. For example: "Felt constantly under strain at work". The occupational context was reminded in the items. Each item is rated on a four-point scale (less than usual, no more than usual, rather more than usual, or much more than usual). The Likert scoring method (0-1-2-3) was used for this study. A higher score indicates a greater degree of psychological distress.

\subsection{Statistical Analysis}

We performed exploratory factor analysis (EFA) to explore the structure of the instrument, with the principal components method. The cutoff of factor loading adopted was $>0.5$ [20].

The reliability of the measure was examined in relation to the instrument's internal consistency by calculating the Cronbach's $\alpha$ coefficient and the homogeneity of the scale (mean inter-item correlations). A Cronbach's $\alpha$ coefficient of 0.70 or greater and mean inter-item correlations situated in a 0.20 to 0.40 range were considered as satisfactory [21]. The means and the variances of all items were computed with 95\% confidence limits.

\section{RESULTS}

\subsection{Descriptive Statistics}

One thousand and fourteen workers, aged 18 - 63 years $($ Mean $=41.5$; SD $=10.3$ ) entered the study. Fifty three percent were male. Demographics of workers who responded to our questionnaire, and comparison with the French working population are shown in Table 1.

Table 2 presents the mean scores (m), standard deviation (SD), and correlations between items of the General Health Questionnaire at Work (GHQW). The item's means range from 0.50 (item 11) to 1.20 (items 1 and 5). The means inter-item correlations of the total set of items was ranged from 0.42 (items 7 and 4) to 0.79 (item 10 and 9).

\subsection{Factor Structure}

Table 2 presents the factor loading produced by the EFA with the principal component method. This analysis identified a single factor model (factor loadings ranging from 0.68 to 0.89 ), explaining $60.5 \%$ of the total variance of the scale.

\subsection{Homogeneity and Reliability}

The 12 items of the GHQW showed good homogeneity. The average inter-item correlation was 0.57 . The items-total correlations were ranged from 0.62 to 0.86 indicating a good contribution to the total score.

The internal consistency of the questionnaire was measured using the Cronbach's $\alpha$ coefficient. This coefficient was found to be 0.94 .

\section{DISCUSSION}

The current study aimed at exploring the structure and reliability of the GHQ-12 adapted to a work-related context (GHQW). We have tried to adapt the GHQ-12, the shorter version of the GHQ, to a work-related context. It could be a very helpful tool in the field of occupational psychology.

There are significant difference between the subjects and French workers. The ratio of the youngest workers is more important in our sample. In fact, there is some differences in the different parts of France. Whatever, there is no influence on the validation. Most of the validation studies was done with samples of students. We prefer an

Table 1. Demographics of subjects and comparison with the French workers.

\begin{tabular}{cccc}
\hline & Subjects $(n=1014)$ & $\begin{array}{c}\text { French workers } \\
(n=27,600,000)\end{array}$ & $p$ \\
\hline Age & $41.5 \mathrm{y}(10.3)$ & $40.2 \mathrm{y}$ & $\mathrm{ns}$ \\
$\begin{array}{c}\text { (mean,(SD)) } \\
<30 \text { years }\end{array}$ & $19.8 \%$ & $13.5 \%$ & $<0.01$ \\
30 - 39 y & $26.3 \%$ & $31.9 \%$ & $<0.01$ \\
$40-49$ y & $28.1 \%$ & $27.6 \%$ & $\mathrm{~ns}$ \\
$>49$ y & $25.7 \%$ & $27 \%$ & $\mathrm{~ns}$ \\
Gender & & & \\
male & $53 \%$ & $53.6 \%$ & $\mathrm{~ns}$ \\
\hline
\end{tabular}

*According the «institut national de la statistique et des études économiques»; ns: $p>0.05$. 
Table 2. Means (m), Standard Deviation (SD) and correlations between items, item-total correlations, and exploratory factorial analysis (EFA) of the General Health Questionnaire at Work (GHQW).

\begin{tabular}{|c|c|c|c|c|c|c|c|c|c|c|c|c|c|c|}
\hline & Item 1 & Item 2 & Item 3 & Item 4 & Item 5 & Item 6 & Item 7 & Item 8 & Item 9 & Item 10 & Item 11 & Item 12 & $\begin{array}{c}\text { Item-total } \\
\text { correlations }\end{array}$ & $\begin{array}{c}\text { EFA: } \\
\text { Factor I }\end{array}$ \\
\hline Item 1 & 1.00 & & & & & & & & & & & & 0.72 & 0.77 \\
\hline Item 2 & 0.59 & 1.00 & & & & & & & & & & & 0.74 & 0.78 \\
\hline Item 3 & 0.52 & 0.47 & 1.00 & & & & & & & & & & 0.62 & 0.71 \\
\hline Item 4 & 0.56 & 0.40 & 0.54 & 1.00 & & & & & & & & & 0.62 & 0.69 \\
\hline Item 5 & 0.55 & 0.66 & 0.46 & 0.43 & 1.00 & & & & & & & & 0.74 & 0.78 \\
\hline Item 6 & 0.59 & 0.70 & 0.50 & 0.51 & 0.67 & 1.00 & & & & & & & 0.81 & 0.84 \\
\hline Item 7 & 0.46 & 0.43 & 0.51 & 0.42 & 0.51 & 0.48 & 1.00 & & & & & & 0.62 & 0.68 \\
\hline Item 8 & 0.58 & 0.52 & 0.49 & 0.56 & 0.48 & 0.59 & 0.48 & 1.00 & & & & & 0.68 & 0.74 \\
\hline Item 9 & 0.62 & 0.71 & 0.56 & 0.52 & 0.73 & 0.77 & 0.56 & 0.58 & 1.00 & & & & 0.86 & 0.89 \\
\hline Item 10 & 0.66 & 0.66 & 0.55 & 0.56 & 0.63 & 0.75 & 0.47 & 0.60 & 0.79 & 1.00 & & & 0.84 & 0.87 \\
\hline Item 11 & 0.55 & 0.56 & 0.54 & 0.50 & 0.58 & 0.66 & 0.44 & 0.52 & 0.69 & 0.78 & 1.00 & & 0.75 & 0.80 \\
\hline Item 12 & 0.53 & 0.51 & 0.56 & 0.46 & 0.57 & 0.54 & 0.65 & 0.50 & 0.66 & 0.58 & 0.56 & 1.00 & 0.71 & 0.76 \\
\hline $\begin{array}{l}\text { Mean } \\
\text { score }\end{array}$ & 1.20 & 1.00 & 1.11 & 0.99 & 1.20 & 0.83 & 1.17 & 1.14 & 0.79 & 0.64 & 0.50 & 1.15 & & $60.5 \%$ ** \\
\hline SD & 0.62 & 0.98 & 0.73 & 0.65 & 0.95 & 0.94 & 0.68 & 0.65 & 1.01 & 0.96 & 0.88 & 0.68 & & \\
\hline
\end{tabular}

*Average inter-item correlation: 0.57 ; Cronbach's $\alpha$ coefficient: $0.94, * *$ total variance of the scale explained by the one factor structure.

“ecological” validation with a worker sample. There is some differences in age structure but our sample is near the French workers' one.

\subsection{Factor Structure}

Although the GHQ-12 was designed as a unidimensional scale, two- and three-factor models have been frequently reported. Currently, the factor structure of the GHQ-12 remains under debate. The World Health Or ganization study of psychological disorders in general health care in 15 different centers indicated that there is substancial factor variation between centers for the GHQ-12 [22].

The inconsistent findings might be partly due to the statistical methods used (principle component analysis with varimax rotation or confirmatory factor analysis), and wording effects (positively and negatively worded items) [23].

But the context might be an important cause of these inconsistent findings. The factor structure of the GHQ12 is often explored in various and specific population, such as elderly adults, students, or physician population. These specific populations refer to their own environment to answer to this questionnaire. An item or a set of items of the GHQ-12 have probably not the same meaning in elderly adults, unemployed population, or students. Moreover, each of these populations can refer to different life events (whether occupational, whether private) for the meaning of the items.

In this study, the structure and reliability of the GHQ12 is explored in a large and almost representative population of French workers, and the items remind the reference context. This work-related version induces a more homogeneous meaning of the set of items, and so probably contributes to the single factor structure and the high reliability of the GHQW.

We use an EFA because we do not have strong theory about the construct underlying responses to our measures in an occupational context. A second study could follow up with a Confirmatory Factor Analysis (CFA) to confirm the factor structure of the GHQW. This CFA cannot be done using the same data set. Whatever, a CFA performed in a large sample of workers is useful.

The high factor loading and its homogeneity consolidate the use of the GHQW as a unidirectional measure. The score of the GHQW can be the sum of the items, without weighting some items.

\subsection{Reliability}

In general, the most research findings throughout the world show satisfactory reliabilities. Cronbach's alpha in our study was 0.94. The internal consistency of the GHQW is over the original French translation of the GHQ-12. (0.78), and close to two French GHQ-28 item alpha, respectively 0.91 and 0.95 [24,25].

We have data from more than 80 subjects for every measured variable in the model, which is widely over the 10 subjects recommended per variable [26]. This large sample provides a good reliability in our parameter estimates.

The specific context of work-related psychological context increases the homogeneity of the GHQW. The findings reported in the current study support the psychometric appropriateness of the GHQW.

We have study the possibility to provide a shorter version of the GHQW. But the good homogeneity of the item-total correlations does not allow it (Table 2).

\section{CONCLUSIONS}

The current study provides some evidences that the 
GHQW is a reliable version (Cronbach's $\alpha$ coefficient: 0.94) and valid instrument for measuring work-related psychological distress The findings reported support a single factor structure, as in the original Goldberg's version.

This version could find some applications in epidemiological research at work, in the study of psychosocial risk factors and in the occupational health physician's daily activity.

\section{REFERENCES}

[1] Goldberg, D.P. and Williams, P. (1988) A user's guide to the General Health Questionnaire. nferNelson, Windsor.

[2] Richardson, A., Plant, H., Moore, S., Medina, J., Cornwall, A. and Ream, E. (2007) Developing supportive care for family members of people with lung cancer: A feasibility study. Supportive Care in Cancer, 15, 1259-1269. doi:10.1007/s00520-007-0233-z

[3] Henkel, V., Mergl, R., Kohnen, R., Maier, W., Möller, H.J. and Hegerl, U. (2003) Identifying depression in primary care: A comparison of different methods in a prospective cohort study. British Medical Journal, 326, 200-201. doi:10.1136/bmj.326.7382.200

[4] Jones, M., Rona, R.J., Hooper, R. and Wesseley, S. (2006) The burden of psychological symptoms in UK Armed Forces. Occupational Medicine, 56, 322-328. doi:10.1093/occmed/kql023

[5] Hardy, G.E., Shapiro, D.A., Haynes, C.E. and Rick, J.E. (1999) Validation of the General Health Questionnaire-12: Using a sample of employees from England's health care services. Psychological Assessment, 11, 159-165. doi:10.1037/1040-3590.11.2.159

[6] Navarro, P., Ascaso, C., Garcia-Esteve, L., Aguado, J., Torres, A. and Martin-Santos, R. (2007) Postnatal psychiatric morbidity: A validation study of the GHQ-12 and the EPDS as screening tools. General Hospital Psychiatry, 29, 1-7. doi:10.1016/j.genhosppsych.2006.10.004

[7] Quek, K.F., Low, W.Y., Razack, A.H. and Loh, C.S. (2001) Reliability and validity of the General Health Questionnaire (GHQ-12) among urological patients: A Malaysian study. Psychiatry and Clinical Neurosciences, 55, 509-513. doi:10.1046/j.1440-1819.2001.00897.x

[8] Tait, R.J., French, D.J. and Hulse, G.K. (2003) Validity and psychometric properties of the General Health Questionnaire-12 in young Australian adolescents. Australian and New Zealand Journal of Psychiatry, 37, 374-381. doi:10.1046/j.1440-1614.2003.01133.x

[9] Hahn, D., Reuter, K. and Harter, M. (2006) Screening for affective and anxiety disorders in medical patients: Comparison of HADs, GHQ-12 and brief-PHQ. GMS Psycho Social Medicine, 3, 1-11.

[10] Graetz, B. (1991) Multidimensional properties of the General Health Questionnaire. Social Psychiatry and Psychiatric Epidemiology, 26, 132-138. doi:10.1007/BF00782952

[11] Salama-Younes, M., Montazeri, A., Ismail, A. and Roncin, C. (2009) Factor structure and internal consistency of the 12-item General Health Questionnaire (GHQ-12) and the Subjective Vitality Scale (VS), and the relation- ship between them: A study from France. Health and Quality of life Outcomes, 7, 22. doi:10.1186/1477-7525-7-22

[12] Shevlin, M. and Adamson, G. (2005) Alternative factor models and factorial invariance of the GHQ-12: A large sample analysis using confirmatory factor analysis. Psychological Assessment, 17, 231-236. doi:10.1037/1040-3590.17.2.231

[13] Claes, R. and Fraccaroli, F. (2002) The General Health Questionnaire (GHQ-12): Factorial invariance in different language versions. Bollettino di Psicologia Applicata, 237, 25-35.

[14] Penninkilampi-Kerola, V., Miettunen, J. and Ebeling, H. (2006) A comparative assessment of the factor structures and psychometric properties of the GHQ-12 and the GHQ-20 based on data from a Finnish population-based sample. Scandinavian Journal of Psychology, 47, 431440. doi:10.1111/j.1467-9450.2006.00551.x

[15] Ip, W.Y. and Martin, C.R. (2006) Factor structure of the Chinese version of the 12-item General Health Questionnaire (GHQ-12) in pregnancy. Journal of Reproductive and Infant Psychology, 24, 87-98. doi:10.1080/02646830600643882

[16] Ip, W.Y. and Martin, C.R. (2006) Psychometric properties of the 12-item General Health Questionnaire (GHQ12) in Chinese women during pregnancy and in the postnatal period. Psychology, Health \& Medicine, 11, 60-69. doi:10.1080/13548500500155750

[17] Vanheule, S. and Bogaerts, S. (2005) Short Communication: The factorial structure of the GHQ-12. Stress and Health: Journal of the International Society for the Investigation of Stress, 21, 217-222.

[18] Lopez-Castedo, A. and Fernandez, L. (2005) Psychometric properties of the Spanish version of the 12-item general health questionnaire in Adolescents. Perceptual and Motor Skills, 100, 676-680. doi:10.2466/PMS.100.3.676-680

[19] Kalliath, T.J., O’Driscoll, M.P. and Brough, P. (2004) A confirmatory factor analysis of the General Health Questionnaire-12. Stress and Health: Journal of the International Society for the Investigation of Stress, 20, 11-20.

[20] Peterson, R.A. (2000) Meta-analysis of variance accounted for and factor loadings in exploratory factor analysis. Marketing Letters, 11, 261-275. doi:10.1023/A:1008191211004

[21] Nunnally, J. and Bernstein, I.H. (1994) Psychometric theory. McGraw-Hill, New York.

[22] Werneke, U., Goldberg, D.P., Yalcin, I. and Ustun, B.T. (2000) The stability of the factor structure of the General Health Questionnaire. Psychological Medicine, 30, 823829. doi:10.1017/S0033291799002287

[23] Ye, S. (2009) Factor structure of the General Health Questionnaire (GHQ-12): The role of wording effect. Personality and Individual Differences, 46, 197-201. doi:10.1016/i.paid.2008.09.027

[24] Pariente, P., Challita, H, Mesba, M and Guelfi, J.D. (1992) The GHQ-28 questionnaire in French: A validationsurvey in a panel of 158 general psychiatric patients. European Psychiatry, 7, 15-20.

[25] Darvez-Bornoz, J.M. and Pierre, F. (1998) Screening for psychologically traumatized rape victims. European Journal of Obstetrics \& Gynecology and Reproductive 
Biology, 77, 71-75. doi:10.1016/S0301-2115(97)00244-3

[26] De Coster, J. (2011) Overview of factor analysis. http://www.stat-help.com/notes.html accessed January $\underline{11,2011}$

\section{APPENDIX: LIST OF THE ITEMS OF THE GHQ-12}

1- Able to concentrate

2- Lost sleep over worry

3- Play useful part in things

4- Capable of making decisions

5- Constantly under strain
6- Could not overcome difficulties

7- Enjoy day-to-day activities

8- Face up problems

9- Feeling unhappy and depressed

10- Losing confidence in self

11- Thinking of self as worthless

12- Reasonable happy 